\title{
PfEMP1 expression is reduced on the surface of knobless Plasmodium falciparum infected erythrocytes
}

\author{
Paul Horrocks ${ }^{1, *}$, Robert A. Pinches ${ }^{1}$, Srabasti J. Chakravorty ${ }^{4}$, Janni Papakrivos ${ }^{5}$, Zóe Christodoulou ${ }^{1}$, \\ Susan A. Kyes ${ }^{1}$, Britta C. Urban ${ }^{2}$, David J. P. Ferguson ${ }^{3}$ and Chris I. Newbold ${ }^{1}$ \\ ${ }^{1}$ Weatherall Institute of Molecular Medicine, ${ }^{2}$ Centre for Clinical Vaccinology and Tropical Medicine and ${ }^{3}$ Nuffield Department of Clinical Laboratory \\ Sciences, University of Oxford, Oxford, OX3 9DS, UK \\ ${ }^{4}$ Liverpool School of Tropical Medicine, Pembroke Place, Liverpool, L3 5QA, UK \\ ${ }^{5}$ FB Biologie, Philipps-Universität Marburg, 35032 Marburg, Germany \\ *Author for correspondence (e-mail: horrocks@ hammer.imm.ox.ac.uk)
}

Accepted 16 March 2005

Journal of Cell Science 118, 2507-2518 Published by The Company of Biologists 2005

doi:10.1242/jcs.02381

\section{Summary}

The Plasmodium falciparum erythrocyte membrane protein 1 (PfEMP1) is a key virulence factor for this species of human malarial parasite. PfEMP1 is expressed on the surface of infected erythrocytes (IEs) and directly mediates adhesion to a variety of host cells. A number of other parasite-encoded proteins are similarly exported to the IE plasma membrane and play an indirect role in this adhesion process through the modification of the erythrocyte cytoskeleton and the formation of electron dense knobs into which PfEMP1 is anchored. Analysis of the specific contribution of knob-associated proteins to adhesion is difficult due to rapid PfEMP1 switching during in vitro culture. Furthermore, these studies typically assume that the level and distribution of PfEMP1 exposed in knobby $\left(\mathrm{K}^{+}\right)$and knobless $\left(\mathrm{K}^{-}\right)$IEs is unaltered, an

assumption not yet supported with data. We describe here the preparation and characterisation of a panel of isogenic $\mathrm{K}^{+}$and $\mathrm{K}^{-}$parasite clones that express one of two defined PfEMP1 variants. Analysis of the cytoadhesive properties of these clones shows that both static and flow adhesion is reduced in all the $\mathrm{K}^{-}$clones and, further, that this correlates with an approximately $\mathbf{5 0 \%}$ reduction in PfEMP1 displayed on the IE surface. However, despite this reduction, the gross distribution of PfEMP1 in $\mathrm{K}^{-}$IEs appears unaltered. These data impact on our current interpretation of the role of knobs in adhesion and the mechanism of trafficking PfEMP1 to the IE surface.

Key words: Plasmodium falciparum, PfEMP1, Trafficking, Cytoadhesion, Knobs

\section{Introduction}

The Plasmodium falciparum erythrocyte membrane protein (PfEMP1) plays a major role in the specific pathology associated with this human malarial parasite species (Kyes et al., 2001; Newbold et al., 1999). PfEMP1 is exposed on the surface of infected erythrocytes (IE), where it mediates adhesion to the host microvasculature. Accumulation of IEs within the microvasculature results in poor blood perfusion leading to organ dysfunction (Rogerson et al., 2004). PfEMP1 is also the target of protective antibody, although clonal antigenic variation of this molecule allows the parasite to evade the host response and establish a chronic infection typical in people residing in malaria endemic regions (Bull et al., 1998; Marsh and Howard, 1986). IE adhesion to dendritic cells also inhibits the maturation of these antigen-presenting cells (Urban et al., 1999). PfEMP1 is thus central to both the pathogenesis of disease and the induction of host immunity.

Cytoadhesion of IEs to endothelial cells is mediated via the interaction of PfEMP1 with a wide range of host receptors (Kyes et al., 2001). The distribution of sequestered parasites is determined by the specific adhesion properties of each PfEMP1 variant and the restriction of host ligand expression on endothelial cells in different tissues. For example, whereas adhesion to CD36 is a common adhesive phenotype for many PfEMP1 variants, adhesion to ligands such as intercellular adhesion molecule 1 (ICAM1, CD54) and chondroitin sulphate A (CSA) are properties of more restricted subsets of PfEMP1 variants (Newbold et al., 1999; Newbold et al., 1997). Adhesion to ICAM1 on endothelial cells in the brain is associated with cerebral malaria (Turner et al., 1994) and adhesion to CSA expressed on syncytiotrophoblasts in the placenta is associated with malaria during pregnancy (Fried and Duffy, 1996). Thus, specific PfEMP1 adhesive properties play an important part in determining the pathology of disease.

Perhaps the most obvious modification to the host erythrocyte is the development of several thousand knob-like protrusions ( $100 \mathrm{~nm}$ diameter) from approximately 16-18 hours post-invasion (Gruenberg et al., 1983; Langreth et al., 1978; Nagao et al., 2000). These electron dense structures act as sites for anchoring PfEMP1 on the outer face of the plasma membrane and are thus implicated in mediating IE cytoadhesion (Baruch et al., 1995; Cooke et al., 2000). Knobs consist of a number of parasite-encoded proteins, including knob-associated histidine-rich protein (KAHRP), PfEMP3 and 
mature IE surface antigen (MESA). Although exported to the IE plasma membrane, these proteins are not exposed on the external face (Coppel et al., 1998; Deitsch and Wellems, 1996). KAHRP is known to be a major structural component of knobs since deletion of the gene encoding this protein results in knobless ( $\mathrm{K}^{-}$) IEs (Crabb et al., 1997). $\mathrm{K}^{-}$IEs exhibit a reduced level of adhesion to endothelial cell lines or purified host ligands, emphasising the key role for knobs and, by extension, KAHRP, in mediating cytoadhesion (Biggs et al., 1989a; Crandall et al., 1994; Udomsangpetch et al., 1989).

It has been suggested that the biological function of knobs is to augment PfEMP1 adhesion under flow (Cooke et al., 2002a; Crabb et al., 1997; Raventos-Suarez et al., 1985). KAHRP interacts directly with both the cytoplasmic tail of PfEMP1 as well as components of a modified IE cytoskeleton (Magowan et al., 2000; Oh et al., 2000; Waller et al., 1999; Waller et al., 2002). These interactions are thought to transmit shear stress forces developed during adhesion under conditions of physiological flow across the entire cytoskeleton of IEs (Crabb et al., 1997). MESA interacts with components of the IE cytoskeleton, although no evidence suggests a similar bridging role between the cytoskeleton and PfEMP1 (Cooke et al., 2002a). An interaction between PfEMP3 and the cytoskeleton has not yet been demonstrated, but this protein is thought to play a role in the efficiency of export of PfEMP1 to the knobs (Waterkeyn et al., 2000).

The level of IE adhesion is therefore influenced not only by the specific adhesion properties of the PfEMP1 variant expressed, but also through the contribution of other parasiteencoded proteins such as KAHRP. Although several studies have investigated the contribution of these non-PfEMP1 knobassociated proteins (Crabb et al., 1997; Cooke et al., 2002a; Waterkeyn et al., 2000) it has not hitherto been possible to compare adhesion of $\mathrm{K}^{+}$and $\mathrm{K}^{-}$IEs expressing the same PfEMP1 variant because, in the absence of selection, rapid transcriptional switching between members of the gene family (var) that encodes PfEMP1 quickly renders an in vitro population heterogeneous with respect to the PfEMP1 variant expressed (Horrocks et al., 2004a; Roberts et al., 1992). Additionally, previous analysis of adhesion by $\mathrm{K}^{+}$and $\mathrm{K}^{-}$IEs assumed that the amount and distribution of PfEMP1 is equivalent in both $\mathrm{K}^{+}$and $\mathrm{K}^{-}$IEs, something that has never been definitively established and which may obviously impact on the nature of the cytoadhesive process.

In an attempt to address these issues, a panel of isogenic $\mathrm{K}^{+}$ and $\mathrm{K}^{-}$clones predominantly expressing one of two different PfEMP1 variants was prepared. The cytoadhesive properties of these clones were defined and the contribution of factors such as the amount, distribution and organisation of PfEMP1 in $\mathrm{K}^{+}$ and $\mathrm{K}^{-}$IEs examined.

\section{Materials and Methods}

\section{Parasite culture}

Intraerythrocytic stages of $P$. falciparum parasites were cultured in vitro as previously described (Trager and Jensen, 1976). Parasite clones used in this study were derived from the A4 clone (Roberts et al., 1992). A4 cultures were selected for adhesion either to the type 41 PfEMP1-variant (equivalent to A4var) specific monoclonal mouse antibody (mAbBC6) or to uninfected erythrocytes (rosetting), prior to cloning by limiting dilution (Horrocks et al., 2004a; Horrocks et al., 2004b; Roberts et al., 1992). A total of 56 clones were derived and provisionally assessed for their knobby phenotype based on the ability of IEs to float on a cushion of Plasmage ${ }^{\mathrm{TM}}$.

\section{Antisera}

The mouse monoclonal antibody (mAb) mAbBC6 was derived in this laboratory (Roberts et al., 1992). Other mAbs used were specific for KAHRP (mAb89), human CD59 (ABCAM, Cambridge) and band 3 (Sigma Aldrich). Polyclonal antiserum to $P$. falciparum aldolase (Knapp et al., 1990), PfExp-1 (Johnson et al., 1994) and the conserved cytoplasmic domain ( $\alpha$-ATS) of type 41 var PfEMP1 (T. Fagan and C.I.N., unpublished) were also used. The $\mathrm{IgG}$ fraction of pooled hyperimmune serum from adult Gambians (adult $\mathrm{IgG}$ ) was isolated using a HiTrap ${ }^{\mathrm{TM}}$ protein $\mathrm{G}$ column (Amersham Biosciences) on a Pump P-500 (Pharmacia) fast-performance liquid chromotography system.

\section{Cytoadhesion assays}

Static adhesion assays using $80 \mu \mathrm{g} \mathrm{m} \mathrm{m}^{-1}$ recombinant ICAM-Fc adsorbed onto plastic were carried out as described (Gardner et al., 1996; Horrocks et al., 2002; Newbold et al., 1997). Data shown here represent the mean number of IEs adhering to $1 \mathrm{~mm}^{2}$ from three independent experiments with the range indicating standard deviation. Binding of IEs to purified CHO cells stably transfected with a CD36 expression construct or non-transfected control cells was performed according to standard procedures (Newbold et al., 1997). Adherent IEs were counted using light microscopy and the number of IEs bound per square millimetre was corrected for binding at $2 \%$ haematocrit and $5 \%$ parasitaemia.

Flow adhesion was investigated using a modified laminar flow system (Cooke et al., 2002b). ICAM1 adhesion was determined using aminopropyl triethoxysilane (APES)-treated microslides coated with recombinant ICAM-Fc at $50 \mu \mathrm{g} \mathrm{m} l^{-1}$ overnight at $4^{\circ} \mathrm{C}$ and blocked with $1 \%$ BSA in phosphate buffer for 2 hours at $37^{\circ} \mathrm{C}$. Adhesion to CD36 was assessed on human dermal microvascular endothelial cells (HDMECs) that had been confirmed by flow cytometry to constitutively express high levels of CD36. HDMECs were seeded on APES-treated microslides coated with $1 \%$ gelatin and $0.25 \mathrm{mg} \mathrm{ml}^{-1}$ collagen. HDMECs were allowed to reach confluence over 24 hours and treated with $0.5 \mathrm{ng} \mathrm{ml}^{-1}$ TNF- $\alpha$ overnight prior to performing the adhesion assay. To block specific adhesion to ICAM1 and CD36, mAb15.2 (Serotec, Oxford, UK) and mAbFA6 (Abcam, Cambridge, $\mathrm{UK})$, respectively, were added to the slides at $5 \mu \mathrm{g} \mathrm{ml}^{-1}$ at $37^{\circ} \mathrm{C}$ for 30 minutes prior to the start of the assay.

IEs suspended in binding medium (RPMI-1640 without bicarbonate, $0.2 \%$ glucose $\mathrm{pH} 7.2$ ) were adjusted to $3 \%$ parasitaemia and $1 \%$ haematocrit and perfused through the microslide for 5 minutes at a flow rate that yielded a shear stress of $0.05 \mathrm{~Pa}$. This was followed by perfusion of cell-free binding medium for a further 2 minutes to remove any non-adherent cells, after which the number of adherent cells were counted in six random fields at $\times 300$ magnification and expressed as cells bound per $\mathrm{mm}^{2}$. Statistical analysis was provided by one-way ANOVA tests (PRISM 4, GraphPad Software).

\section{Southern and northern blot analysis}

Hybridization of radiolabelled probes and subsequent high stringency washes to size-fractionated endonuclease-restricted genomic DNA or chromosomal DNA was carried out as described (Horrocks et al., 2002). Accurate positions for the chromosome 2 breakpoints in clones 2F6, 2A12 and 1C10 were identified following PCR amplification of genomic DNA between an oligonucleotide complementing $P$. falciparum telomere repeat sequences and a series of primers between $\mathrm{PfB} 0100 \mathrm{c}$ and $\mathrm{PfB} 0105 \mathrm{c}$ directed towards the telomere. Products were cloned into a commercial PCR cloning vector (Invitrogen) and 
sequenced using dRhodamine terminator cycle sequencing (PE Applied Biosystems).

Total RNA $(5 \mu \mathrm{g})$ was isolated from ring IEs and size-fractionated on a $0.8 \%$ agarose gel containing $5 \mathrm{mM}$ guanidine thiocyanate (Kyes et al., 2000). Subsequent blotting, hybridisation and radiolabelled probe preparation were performed as described (Kyes et al., 2003). Following confirmation of a single predominant var transcript using a conserved exon II probe (Kyes et al., 2003), RT-PCR using redundant oligonucleotides designed to semi-conserved sequences in the duffy-binding-like $1 \alpha$ domain (DBL1 $\alpha$ ) was used to identify the specific var variant transcribed (Horrocks et al., 2002). Probes used in northern blots were designed to the DBL1 $\alpha$ of the A4 clone var gene variants types 6 and 41 (AJ319684 and AJ319711), ef-1 $\alpha$ (PF11_0245) and kahrp (PfB0100c).

\section{Western blot analysis and urea extraction}

Trophozoite-stage parasites were isolated from $2 \times 10^{8}$ IEs by lysis of the erythrocytes in 10 volumes of $0.1 \%$ saponin in PBS. Released parasites were collected by low-speed centrifugation (3000 g, 10 minutes, $4^{\circ} \mathrm{C}$ ), washed in PBS and solubilised in SDS-loading buffer. Proteins were subjected to SDS-PAGE (10\% polyacrylamide), electroblotted to nitrocellulose and immunodetection carried out using peroxidase-conjugated swine anti-rabbit or rabbit anti-mouse secondary antibody (DAKO) and ECL reagents (Amersham Biosciences). Treatment of IEs with a low concentration of trypsin cleaves off the majority of the surface exposed moiety of PfEMP1 leaving a smaller trypsin-resistant product of approximately $80 \mathrm{kDa}$ (Gardner et al., 1996). Trophozoite IEs were incubated for 5 minutes in $100 \mu \mathrm{g} \mathrm{ml}^{-1}$ trypsin (TCPK treated, Sigma) in serum-free medium. The reaction was stopped by the addition of $2 \mathrm{mg} \mathrm{ml}^{-1}$ trypsin inhibitor (III-O chicken egg white, Sigma). IEs were washed in complete medium before processing for western blot. Urea extractions were carried out using $2 \times 10^{8}$ trophozoite IEs as described (Papakrivos et al., 2005).

\section{Flow cytometry}

Trophozoite IEs were incubated with various concentrations of either mAb-BC6 or adult IgG. Labelled IEs were incubated with either rabbit anti-mouse IgG (DAKO) or pre-adsorbed rabbit anti-human $\mathrm{C}_{\mathrm{H}} 2$ (DAKO) before addition of FITC-conjugated swine anti-rabbit IgG (DAKO) with ethidium bromide $\left(1 \mu \mathrm{g} \mathrm{ml}^{-1}\right)$. The proportion of FITC/EtBr-stained IEs as a proportion of all IEs was determined as well as the mean fluorescence intensity (MFI) of FITC labelling using a FACScalibur flow cytometer (Becton Dickinson). Subsequent data analysis was performed using WinMDI v2.8 (http://facs.scripps.edu) and PRISM4 (GraphPad Software).

\section{Indirect immunofluorescence assay}

Trophozoite IEs washed in PBS were labelled with mAbBC6 or $\alpha$ $\mathrm{CD} 59$ in $\mathrm{PBS} / 1 \% \mathrm{BSA}$ at a range of temperatures $\left(4-37^{\circ} \mathrm{C}\right)$. Over this temperature range, no difference in the pattern of fluorescence was observed. Binding of primary antibodies was detected using rabbit anti-mouse IgG (DAKO) and FITC-conjugated swine anti-rabbit IgG at the same temperature as the primary labelling step. During incubation with the tertiary antibody, nuclei were stained with DAPI at $10 \mu \mathrm{g} \mathrm{ml}^{-1}$ (Sigma). Labelled IEs were wet-mounted beneath a coverslip and examined using either a Zeiss Axioskop microscope fitted with a Hamamatsu C4742-95 cooled digital camera or a Ziess 510 laser scanning confocal microscope. KAHRP was detected using mAb89 as a primary antibody on thin smears of trophozoite IEs fixed with methanol/acetone $(1: 1)$ at $-20^{\circ} \mathrm{C}$ for 10 minutes with subsequent labelling and imaging carried out as described above.

\section{Electron microscopy}

Samples for scanning electron microscopy were fixed in 100 volumes of $4 \%$ glutaraldehyde in $0.1 \mathrm{M}$ sodium phosphate buffer $(\mathrm{pH} 7.2)$, dehydrated and critical point dried. Cells were mounted on stubs before 'sputter' coating with gold prior to examination in a Philips 505 scanning electron microscope. To examine cytoadhesion by transmission electron microscopy (TEM), IEs and HDMECs grown on thermolux coverslips were fixed as described above and post-fixed with osmium tetroxide, dehydrated and embedded in epoxy resin. Thin sections were stained with lead citrate and uranyl citrate before examination in a Joel 1200EX transmission electron microscope. For immuno-TEM, a pre-embedding technique was used. Trophozoite stage IEs were first labelled with $0.5 \mu \mathrm{g} \mathrm{ml}^{-1} \mathrm{mAbBC} 6$ in PBS/1\% $\mathrm{BSA}$ at $25^{\circ} \mathrm{C}$. Reactions performed at $4^{\circ} \mathrm{C}$ and $15^{\circ} \mathrm{C}$ gave identical labelling patterns. IEs were subsequently incubated with rabbit antimouse IgG (DAKO) and goat anti-rabbit IgG conjugated to $10 \mathrm{~nm}$ gold particles (Biocell International Ltd, Cardiff). Labelled IEs were fixed and processed as described above. Numbers of gold particle clusters per IE and their size distribution were counted in a random selection of 200 IEs from three independent labelling experiments of $\mathrm{K}^{+}$and $\mathrm{K}^{-}$IEs then analysed using a Mann-Witney U-test in the STATA6.0 Statistical Data package (Stata Corp.).

For freeze fracture examination, samples were fixed as above and impregnated with $20 \%$ glycerol prior to freezing using liquid nitrogen. Samples were fractured using a Balzer freeze fracture apparatus at $-120^{\circ} \mathrm{C}$ and surface replica formed immediately. After cleaning, the replicas were examined using a Joel 1200EX transmission electron microscope.

\section{Results \\ Preparation and characterisation of isogenic $\mathrm{K}^{+}$and $\mathrm{K}^{-}$ clones expressing defined PfEMP1 variants}

A panel containing a total of 56 isogenic clones was derived from the P. falciparum A4 clone following selection of IEs for adhesion to either uninfected erythrocytes (rosetting) or a PfEMP1 type 41 specific monoclonal antibody (mAbBC6) (Fig. 1A). Selection of parasites immediately prior to cloning restricts the var repertoire transcribed, resulting in a higher proportion of clones that transcribe a single var gene variant (Horrocks et al., 2004a). Clones expressing type 41 PfEMP1 were readily identified from A4 parasites subjected to three rounds of mAbBC6-selection prior to cloning. Clones isolated from rosette-selected cultures transcribe several var gene variants, of which type 6 was relatively common although IEs expressing this variant do not rosette (Horrocks et al., 2004a; Horrocks et al., 2004b). The knobby phenotype of all these clones was initially assessed using a simple test based on the failure of $\mathrm{K}^{-}$trophozoite stage IEs to float in a gelatin solution. Although pairs of $\mathrm{K}^{+}$and $\mathrm{K}^{-}$clones transcribing var type 6 were readily identified (Table 1, Fig. 1A,D), no $\mathrm{K}^{-}$clones predominantly transcribing var type 41 were identified by this method. Therefore, two $\mathrm{K}^{-}$clones, $1 \mathrm{C} 10$ and 2F6 (originally rosette-selected clones), transcribing var types 6 and 14 , respectively, were subjected to two rounds of mAbBC6 selection. The resulting clones, $1 \mathrm{C} 10^{\mathrm{B}}$ and $2 \mathrm{~F} 6^{\mathrm{B}}$, retained their $\mathrm{K}^{-}$phenotype while predominantly expressing type 41 PfEMP1 (75-80\% mAbBC6 positive). Scanning electron microscopy (SEM) confirmed the $\mathrm{K}^{+}$or $\mathrm{K}^{-}$phenotype of the final 8 clones selected (Fig. 1E,F).

Analysis of the karyotype of the 8 clones indicated that all the $\mathrm{K}^{-}$clones bear a truncated chromosome 2. Spontaneous deletion of one arm of chromosome 2 during in vitro culture 
Fig. 1. Molecular characterisation of isogenic knobby and knobless clones. (A) Schematic describing the preparation of isogenic clones used in this study. Rosette or mAbBC6 selected cultures were cloned by limiting dilution. Clones that share the same knobby phenotype and express the same PfEMP1 variant are boxed together. The $\mathrm{K}^{-}$clones expressing type 41 PfEMP1 variant were selected from clones originally cloned from rosetting parasites. See Table 1. (B) Schematic of the chromosome 2 breakpoints in the $\mathrm{K}^{-}$ clones used in this study. The positions of the breakpoints upstream of the kahrp (PFB0100c) gene are indicated, with the distance from the telomere (located on left as a black semi-circle) indicated in kilobase pairs. All genes located to the left of the breakpoint are deleted. (C) Ethidium bromide staining of sizefractionated chromosomes shows that approximately 100 kilobase pairs is deleted from chromosome 2 in the $\mathrm{K}^{-}$ clones. One from each pair of clones (name and knobby phenotype indicated) is shown here. (D) Northern blot analysis indicates specific transcription of var types 41 and 6 in the cloned parasites. Hybridisation with kahrp and $E F-1 \alpha$ probes confirms the ethidium bromide (EtBr) staining indicating equal loading of RNA and that the kahrp gene is not transcribed in $\mathrm{K}^{-}$clones.

Transcript sizes are indicated in kilobases (kb). (E) Scanning electron micrograph of a $\mathrm{K}^{+} \mathrm{IE}$ adhering to a HDMEC monolayer. Note the numerous knobs (k) on the IE plasma membrane. Bar, $1 \mu \mathrm{m}$. (F) Scanning electron micrograph of a $\mathrm{K}^{-} \mathrm{IE}$ adhering to a HDMEC monolayer illustrating the irregular shape of the IE and the absence of knobs on the plasma membrane. Bar, $1 \mu \mathrm{m}$.

typically occurs adjacent to the kahrp gene, some $100 \mathrm{~kb}$ from the telomere, deleting this gene and all those located telomeric to it (Fig. 1B,C) (Biggs et al., 1989b; Lanzer et al., 1994). Chromosome breakpoints in the $\mathrm{K}^{-}$clones $2 \mathrm{~F} 6,2 \mathrm{~A} 11$ and 1C10 were mapped to sites 2080, 2830 and 4300 base pairs upstream of kahrp, respectively. Northern blot analysis confirms the lack of kahrp transcript in the $\mathrm{K}^{-}$clones (Fig. 1D).

Analysis of the absolute and relative levels of adhesion by IEs expressing types 6 and 41 PfEMP1 variants was initially made by static adhesion assays to purified ICAM1 or chondroitin sulphate A (CSA) adsorbed onto plastic or to CD36 expressed on a confluent $\mathrm{CHO}$ cell culture. Analysis of the adhesive profiles of the $\mathrm{K}^{+}$clones confirms the known adherent properties of the expressed PfEMP1 variants. IEs expressing type 41 PfEMP1 adhere to ICAM1 and CD36, whereas those expressing type 6 PfEMP1 only adhere to CD36 (Fig. 2A,B). Adhesion to CD36 is higher in IEs expressing the type 41 PfEMP1 than those expressing type 6 PfEMP1 (Fig. $2 \mathrm{~A}, 1.54$ fold, $P<0.005)$. Neither PfEMP1 variant appears to bind to CSA (data not shown).

Comparison of the level of adhesion in $\mathrm{K}^{+}$and $\mathrm{K}^{-}$clones expressing the same PfEMP1 variant shows that this is reduced in $\mathrm{K}^{-}$IEs irrespective of the PfEMP1 variant expressed. $\mathrm{K}^{-}$ clones expressing type 41 PfEMP1 show reduced adhesion to both ICAM1 and CD36, although owing to variance in the data not all comparisons to the $\mathrm{K}^{+}$clones were significant (Fig. $2 \mathrm{~A}, \mathrm{~B})$. However, the level of adhesion of $\mathrm{K}^{-}$clones expressing type 6 PfEMP1 to CD36 was significantly reduced in all comparisons with the $\mathrm{K}^{+}$clones (Fig. $2 \mathrm{~A}, P<0.001$ ).

Table 1. Phenotypic and transcriptional properties of the panel of isogenic clones

\begin{tabular}{lccl}
\hline Clone & Var type & Knobby phenotype & \multicolumn{1}{c}{ Source } \\
\hline $2 \mathrm{~B} 2$ & 41 & $\mathrm{~K}^{+}$ & Horrocks et al., 2004a \\
2E3 & 41 & $\mathrm{~K}^{+}$ & Horrocks et al., 2004a \\
$1 \mathrm{C} 10^{\mathrm{B}}$ & 41 & $\mathrm{~K}^{-}$ & This study \\
$2 \mathrm{~F} 6^{\mathrm{B}}$ & 41 & $\mathrm{~K}^{-}$ & This study \\
$2 \mathrm{H} 3$ & 6 & $\mathrm{~K}^{+}$ & Horrocks et al., 2004a \\
$3 \mathrm{C} 3$ & 6 & $\mathrm{~K}^{+}$ & Horrocks et al., 2004a \\
$1 \mathrm{C} 10$ & 6 & $\mathrm{~K}^{-}$ & Horrocks et al., 2004a \\
$2 \mathrm{~A} 11$ & 6 & $\mathrm{~K}^{-}$ & Horrocks et al., 2004a \\
\hline
\end{tabular}


Adhesion of $\mathrm{K}^{+}$and $\mathrm{K}^{-}$IEs to ICAM1 and CD36 was further investigated under laminar flow conditions that mimic the microvasculature environment (shear stress of $0.05 \mathrm{~Pa}$ ). Adhesion of type 41 PfEMP1 IEs to recombinant ICAM1 was significantly lower in $\mathrm{K}^{-}$IEs (Fig. 2C, $P<0.0001)$. The specificity of adhesion was confirmed by the use of an ICAM1 blocking antibody (Fig. 2C). $\mathrm{CHO}$ cells grow poorly as a monolayer, so human dermal microvascular endothelial cells (HDMECs), which constitutively express high levels of CD36, were chosen to investigate adhesion by type 6 PfEMP1 under flow. Again, significantly less $\mathrm{K}^{-}$IEs adhere to CD36 $(P<0.01)$, with the specificity of adhesion confirmed by the ablation of adhesion in the presence of a CD36 blocking antibody (Fig. 2D).

\section{$\mathrm{K}^{-}$parasites expose less PfEMP1} on the IE surface

Using $\mathrm{K}^{+}$and $\mathrm{K}^{-}$clones transcribing var type 41, the level of PfEMP1 expressed on the IE surface was examined using flow cytometry with mAbBC6. Two output variables from this analysis were compared. First, the proportion of the IE population labelled with mAbBC6, revealed that recognition of $\mathrm{K}^{+}$and $\mathrm{K}^{-}$clones expressing type 41 PfEMP1 was almost indistinguishable over the range of mAbBC6 concentrations used in this assay (Fig. 3A). Although only $75-80 \%$ of the $\mathrm{K}^{-}$IE populations express type 41 PfEMP1, compared with $85 \%$ of $\mathrm{K}^{+}$ clones, these clones had only been selected twice with mAbBC6 compared to three rounds of selection for the $\mathrm{K}^{+}$ clones. However, comparison of the second output variable, the mean fluorescence intensity (MFI), indicated a clear difference between $\mathrm{K}^{+}$and $\mathrm{K}^{-}$clones (Fig. 3B). $\mathrm{K}^{-}$clones show a reduced level of MFI, which suggests that these IEs express less PfEMP1 on their surface. Under conditions of apparent mAbBC6 saturation $\left(>5 \mu \mathrm{g} \mathrm{ml}{ }^{-1}\right.$ ), the MFI of $\mathrm{K}^{-}$IEs expressing type 41 PfEMP1 is reduced by $30-35 \%$ compared with $\mathrm{K}^{+}$clones.

Flow cytometry analysis was also performed using an $\mathrm{IgG}$ fraction purified from pooled serum derived from African adults from a malaria endemic region (adult $\mathrm{IgG}$ ). The adult $\operatorname{IgG}$ fraction allows analysis of a pair of $\mathrm{K}^{+}$and $\mathrm{K}^{-}$type 6 PfEMP1-expressing clones in the absence of a specific monoclonal antibody reagent. Comparison of the proportion of IEs recognised by adult $\mathrm{IgG}$ again indicates that $\mathrm{K}^{+}$and $\mathrm{K}^{-}$ clones expressing the type 6 PfEMP1 variant are almost

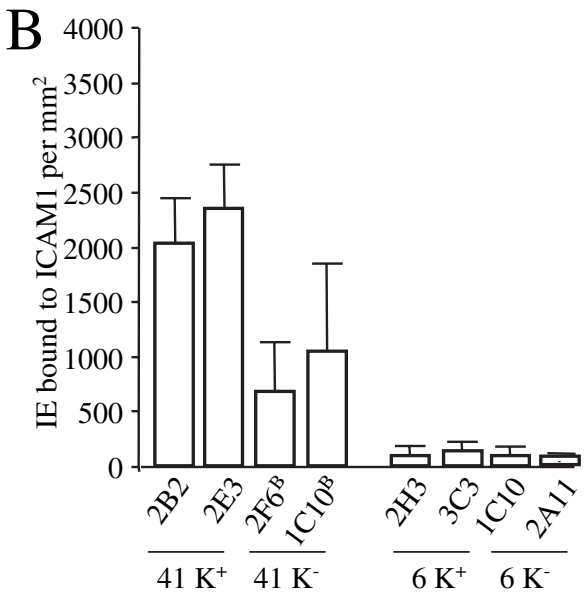

$\mathrm{D}$

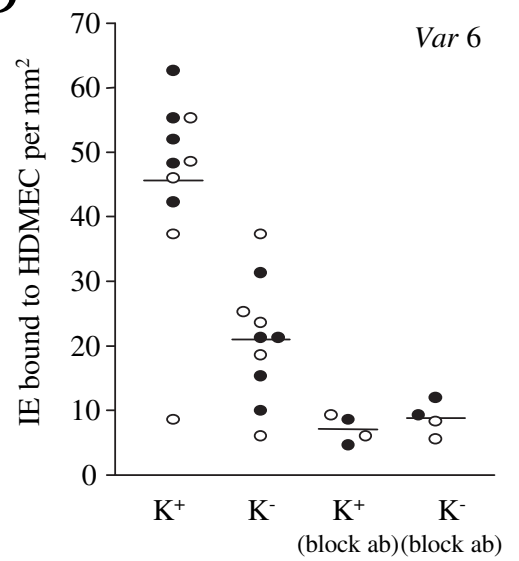

Fig. 2. Static and flow adhesion is reduced in $\mathrm{K}^{-}$clones. (A) Results of static adhesion assays to CD36. The data are representative of four independent experiments (means \pm s.d.). The var variant transcribed and the knobby phenotye is indicated below each clone. (B) Results of (means \pm s.d.). (C) Flow adhesion of var type 41-expressing clones to recombinant ICAM1. from $2 \mathrm{~B} 2\left(\mathrm{~K}^{+}\right)$and $2 \mathrm{~F}^{\mathrm{B}}\left(\mathrm{K}^{-}\right)$; white dots represent $2 \mathrm{E} 3\left(\mathrm{~K}^{+}\right)$and $1 \mathrm{C}^{1} 0^{\mathrm{B}}\left(\mathrm{K}^{-}\right)$. Data generated in the presence of ICAM-1 blocking antibodies are indicated by (block ab). Horizontal bars Black dots represent data derived from $3 \mathrm{C} 3\left(\mathrm{~K}^{+}\right)$and $1 \mathrm{C} 10\left(\mathrm{~K}^{-}\right)$; white dots represent $2 \mathrm{H} 3$ $\left(\mathrm{K}^{+}\right)$and $2 \mathrm{~A} 11\left(\mathrm{~K}^{-}\right)$. The presence of CD36 blocking antibodies is indicated by (block ab). Horizontal bars represent the mean.

indistinguishable (Fig. 3C). Comparison of the MFI between $\mathrm{K}^{+}$and $\mathrm{K}^{-}$clones again suggests that there is less type 6 PfEMP1 on the surface of $\mathrm{K}^{-}$IEs, although conditions necessary for adult IgG saturation were not reached in this analysis (Fig. 3D). Analysis of type 41 PfEMP1-expressing clones using adult IgG supports the finding that the MFI signal in $\mathrm{K}^{-}$clones is reduced (Fig. 3E,F). Moreover, since the level of reduction of MFI is comparable between $\mathrm{mAbBC6}$ and adult IgG-stained IE, this would suggest that the adult IgG fraction predominantly recognises PfEMP1 on the IE surface.

Western blot analysis with a polyclonal serum raised against the C-terminus of the type 41 PfEMP1 was carried out to confirm that $\mathrm{K}^{-}$IEs express less PfEMP1. Densitometry analysis of the $330 \mathrm{kDa}$ type 41 PfEMP1 signal (Fig. 4) from equal numbers of trophozoite IEs isolated from $\mathrm{K}^{+}$and $\mathrm{K}^{-}$ 


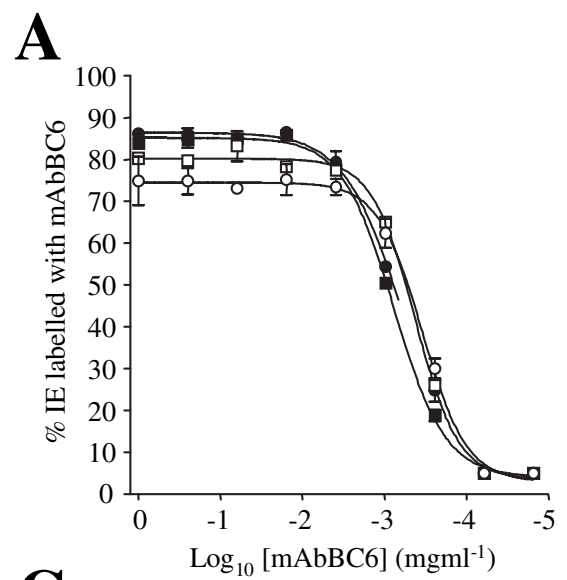

C

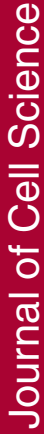

B
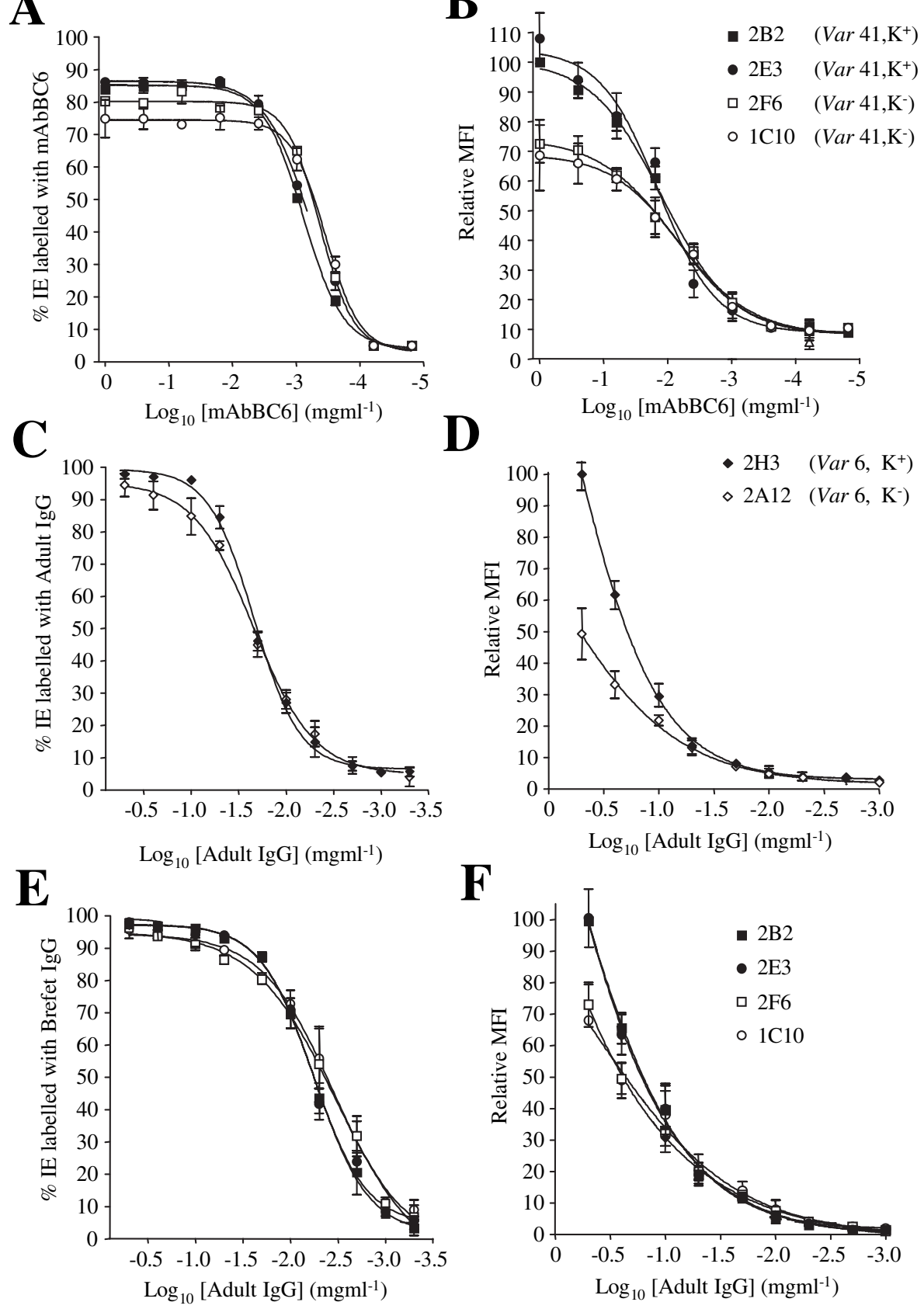

F

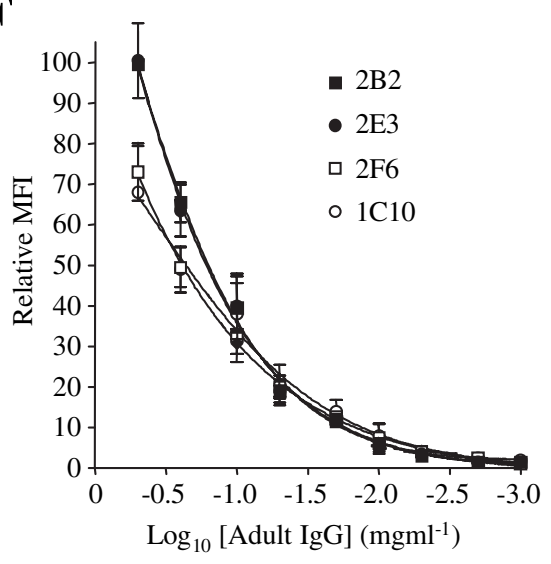

Fig. 3. Determination of the relative levels of surface PfEMP1 by flow cytometry. (A) Graph showing the proportion of type 41 PfEMP1-expressing IEs labelled with mAbBC6 as a function of the concentration of mAbBC6. MAbBC6 labelling of $\mathrm{K}^{+}$ clones (solid symbols) is indistinguishable from that of $\mathrm{K}^{-}$clones (open symbols). All analyses are representative of three independent experiments (mean \pm s.d.). (B) Graph showing the relative level of the mean fluorescence intensity (relative MFI; compared to the $\mathrm{K}^{+}$clone $2 \mathrm{~B} 2$ ) of type 41 PfEMP1-expressing IEs as a function of the concentration of mAbBC6. The key describes the symbols used, the var variant transcribed and the knobby phenotype for each clone in panels A and B. (C) Graph showing the proportion of IEs expressing var 6 PfEMP1 labelled with IgG from pooled adult hyperimmune serum (Adult $\mathrm{IgG})$ as a function of the concentration of IgG. (D) Graph showing the relative MFI (compared to 2H3) of adult IgG-labelled IEs as a function of the concentration of $\mathrm{IgG}$. (E) Graph showing the proportion of IEs expressing var 41 PfEMP1 labelled with adult $\mathrm{IgG}$ as a function of the concentration of IgG. (F) Graph showing the relative MFI (compared to 2B2) of adult IgG-labelled IEs as a function of the concentration of $\mathrm{IgG}$.

Signals from Exp-1 and aldolase, parasite-encoded proteins found within the parasitophorous vacuole and parasite cytoplasm, respectively, indicate matched loading of samples and that IEs remain intact during treatment with trypsin (Fig. 4). Further, the signals obtained from KAHRP indicate matched loading in $\mathrm{K}^{+}$IEs and the lack of expression of this protein in $\mathrm{K}^{-}$IEs (Fig. 4).

Both western blot and flow cytometry analysis provide indirect measurement of a reduced level of expression of PfEMP1 on the surface of $\mathrm{K}^{-}$IEs. Surface-specific iodination using ${ }^{125} \mathrm{I}$

clones indicates a $55 \%$ reduction in signal intensity in $\mathrm{K}^{-}$IEs. In order to discern the contribution that surface-exposed PfEMP1 makes to this reduced total pool of PfEMP1, $\mathrm{K}^{+}$and $\mathrm{K}^{-}$IEs were treated with trypsin prior to harvesting for western blot analysis. Whereas approximately $95 \%$ of the type 41 PfEMP1 pool in $\mathrm{K}^{+}$parasites is exposed on the IE surface and thus removed by tryptic cleavage, only $65 \%$ of the total PfEMP1 pool in $\mathrm{K}^{-}$parasites appears to be similarly exposed (Fig. 4). The efficiency of PfEMP1 export in the $\mathrm{K}^{+}$clones used here compared with $\mathrm{K}^{+} 3 \mathrm{D} 7$, where only approximately $50 \%$ is similarly exposed on the IE surface (Waterkeyn et al., 2000), probably reflects differences in the parasites clones employed in these respective studies. The 3D7 clone appears to have an inherent deficiency in PfEMP1 export (C.I.N., unpublished). was used to confirm this finding. In both $\mathrm{K}^{+}$and $\mathrm{K}^{-}$IEs, iodinated PfEMP1 is present within a Triton X-100-insoluble fraction that is sensitive to trypsin treatment. Comparison of these fractions from equivalent numbers of $\mathrm{K}^{+}$and $\mathrm{K}^{-}$IEs shows a reduction in the intensity of the type 41 PfEMP1 signal by some $50 \%$ (data not shown).

\section{PfEMP1 is similarly distributed on the surface of both $\mathrm{K}^{+}$ and $\mathrm{K}^{-}$IEs}

Following the observation that $\mathrm{K}^{-}$clones appear to express less PfEMP1 on the IE surface, we next examined the possibility that PfEMP1 is alternatively distributed in these parasites. An initial characterisation was carried out using indirect 


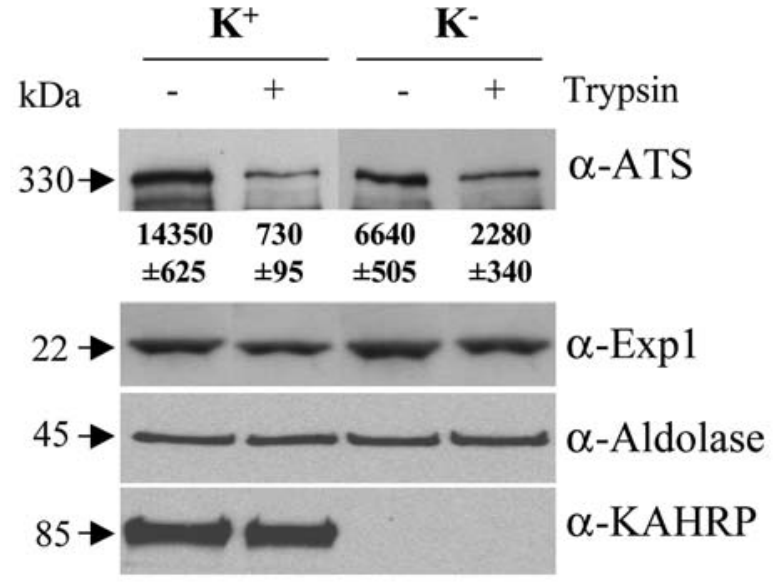

Fig. 4. Less PfEMP1 is expressed on the surface of $\mathrm{K}^{-}$IE. Western blot analysis of whole cell extracts isolated from $\mathrm{K}^{+}$and $\mathrm{K}^{-}$ trophozoite IEs expressing type 41 PfEMP1. Size-fractionated extracts were hybridised with antibodies to either the conserved Cterminus of type 41 PfEMP1 ( $\alpha$-ATS), Exp1, aldolase or KAHRP. Fractions were also isolated from trypsin-treated ( 5 minutes in 100 $\mu \mathrm{g} \mathrm{ml}^{-1}$ ) IEs. The mean and range of three densitometry measurements of the $\alpha$-ATS signal are indicated. Equal signal intensities to KAHRP, Exp-1 and aldolase confirm equal loading of protein extracts and the lack of KAHRP expression in $\mathrm{K}^{-}$IEs. The molecular weights of proteins labelled are indicated $(\mathrm{kDa})$.

immunofluorescence (IFA) with mAbBC6 on type 41 PfEMP1 $\mathrm{K}^{+}$and $\mathrm{K}^{-}$clones. The fluorescence signal associated with surfaceexposed PfEMP1 in a lateral section through the centre of a $\mathrm{K}^{+} \mathrm{IE}$ has previously been described as punctate and distributed over the periphery of the erythrocyte plasma membrane (Kriek et al., 2003; Wickham et al., 2001). Findings here confirm this pattern of PfEMP1 distribution in the $\mathrm{K}^{+}$clones used here, but also show that this pattern of distribution is unchanged in $\mathrm{K}^{-}$clones (Fig. 5A). The pattern of PfEMP1 distribution is clearly distinct from that of the erythrocyte membrane protein CD59, which shows a continuous distribution of fluorescence signal over a lateral section of

Fig. 5. PfEMP1 on the surface of $\mathrm{K}^{+}$and $\mathrm{K}^{-}$IEs appears to share a punctate and static distribution. (A) IFA of either unfixed (mAbBC6 and $\alpha$-CD59) or acetone-fixed ( $\alpha$-KAHRP) type 41 PfEMP1expressing $\mathrm{K}^{+}$and $\mathrm{K}^{-} \mathrm{IE}$. Binding of antibody reagents to IEs was detected using FITCconjugated $\operatorname{IgG}$ (green) in the presence of the nuclear DAPI stain (blue). For each image the corresponding bright field image is shown. A Zplane towards the centre of an IE is shown. Bar, 5 $\mu \mathrm{m}$. (B) IFA of mAbBC6 stained type 41 PfEMP1-expressing $\mathrm{K}^{+}$and $\mathrm{K}^{-}$IEs. The Z-plane has been selected to show the exterior face of the IE. Time-lapse photographs (0, 3 and 6 minutes) of the fluorescence signals are shown. Bar, $5 \mu \mathrm{m}$. the erythrocyte plasma membrane (Fig. 5A). Using acetonefixed and permeabilised IE, the fluorescence signal associated with KAHRP was shown, as expected, to be evenly distributed over the IE plasma membrane periphery only in $\mathrm{K}^{+}$IEs (Fig. $5 \mathrm{~A})$. The resolution of IFA would suggest that the punctate pattern of PfEMP1 distribution is not the result of localisation on knobs, but rather that some regions of the $\mathrm{K}^{+} \mathrm{IE}$ surface bear knobs that are not loaded with PfEMP1.

IFA examination of a Z-plane that encompasses only IE membrane better illustrates the punctate fluorescence signal distribution in both $\mathrm{K}^{+}$and $\mathrm{K}^{-}$clones (Fig. 5B). Time-lapse photography of a single IE over 6 minutes was used to investigate potential changes in the pattern of PfEMP1 fluorescence. No discernible lateral diffusion of fluorescence signal was observed in several examples of either $\mathrm{K}^{+}$or $\mathrm{K}^{-}$ clones (Fig. 5B). The lack of lateral diffusion of PfEMP1 in $\mathrm{K}^{-}$clones would suggest that this molecule, even in the absence of knobs, is statically anchored within the plasma membrane. The biophysical properties of PfEMP1 in $\mathrm{K}^{-}$IEs also appear to be unaltered. PfEMP1 from both $\mathrm{K}^{+}$and $\mathrm{K}^{-}$IEs is present in insoluble fractions following Triton X-100 extraction (data not shown). Similarly, PfEMP1 from both $\mathrm{K}^{+}$and $\mathrm{K}^{-}$IEs is preferentially located within the soluble fraction following urea extraction. PfEMP1 in $\mathrm{K}^{-}$IEs appears, as previously demonstrated for $\mathrm{K}^{+}$IEs (Papakrivos et al., 2005), not to be organised as a classic integral membrane protein but rather shares urea extraction properties more similar to cytoskeletal proteins such as spectrin (data not shown).

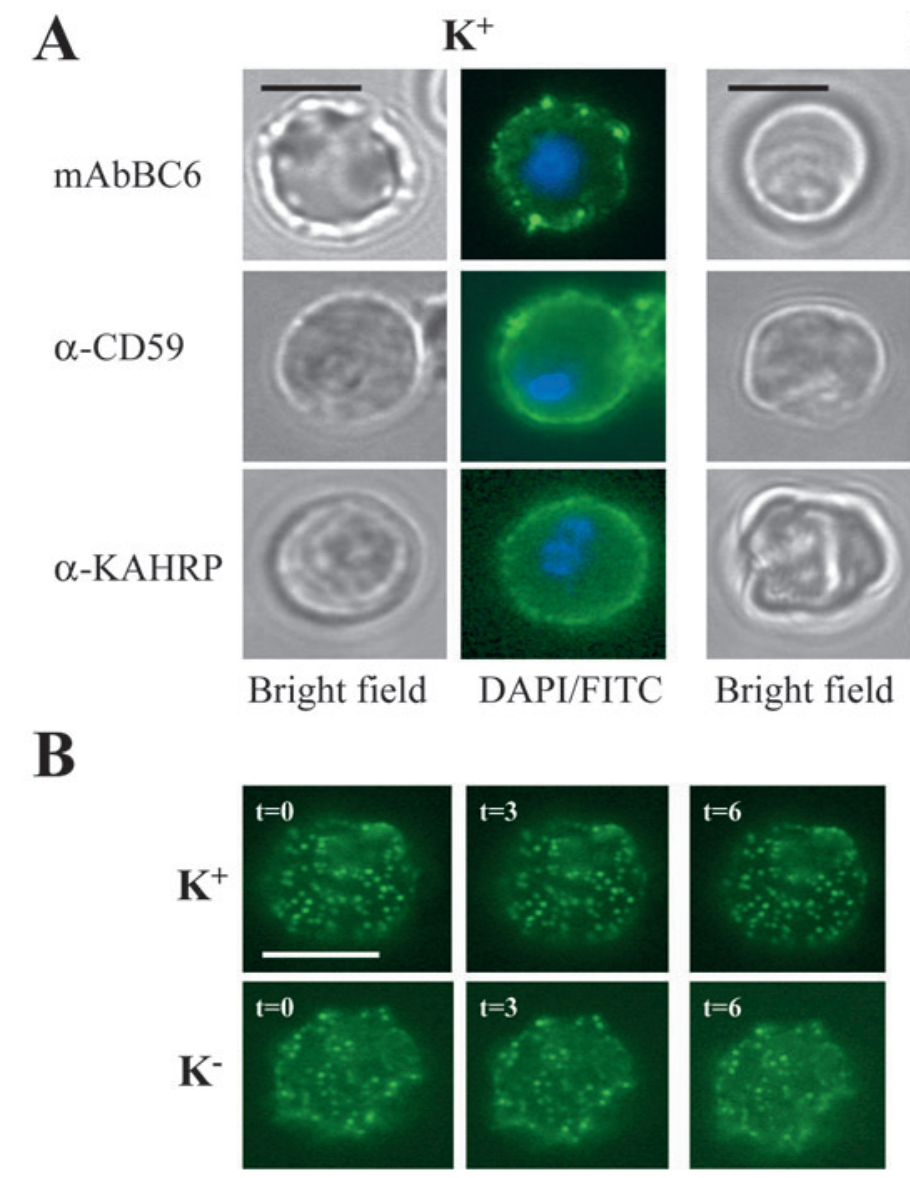

$\mathbf{K}^{-}$
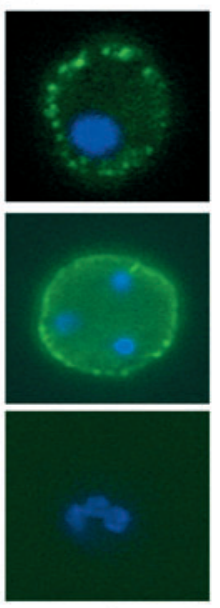

DAPI/FITC 
A
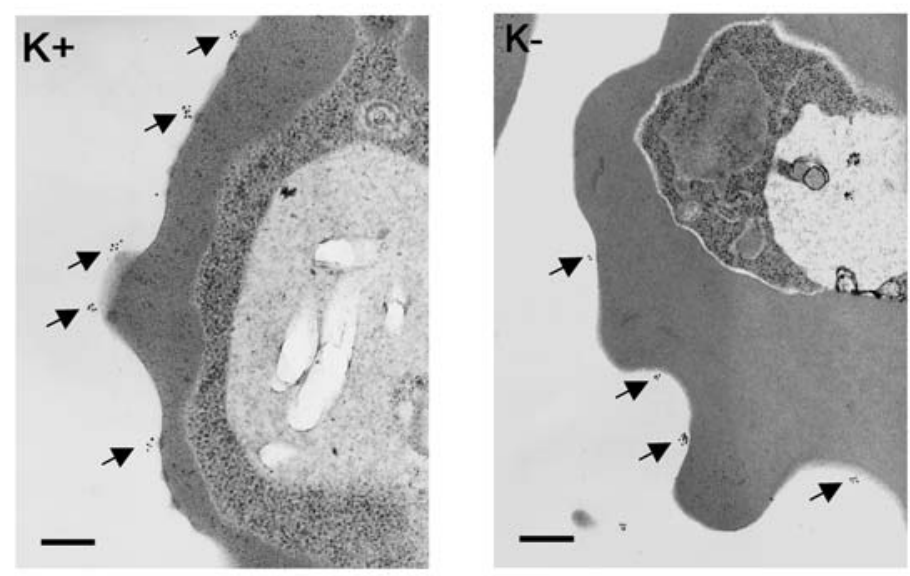

B
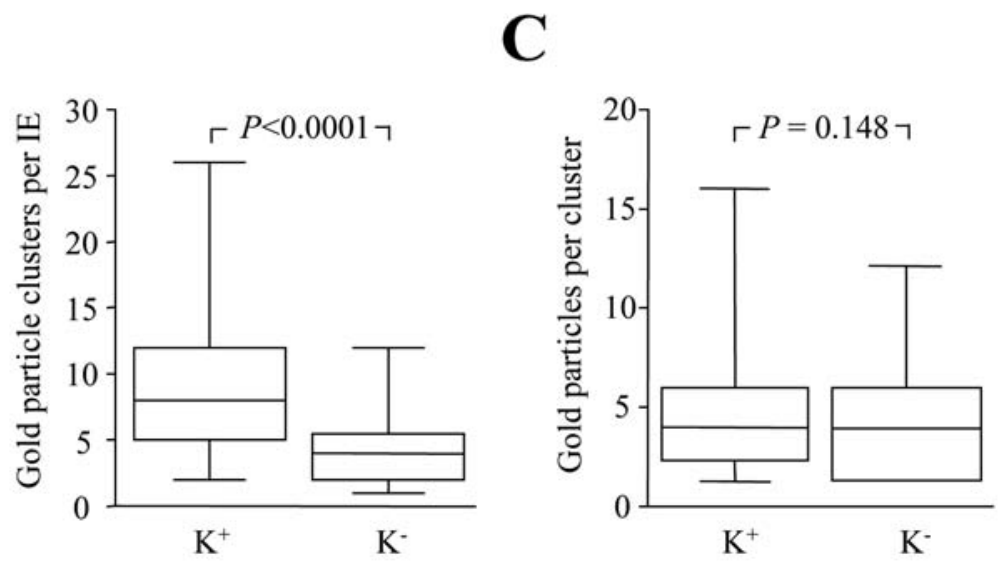

Fig. 6. TEM analysis of PfEMP1 distribution on the surface of $\mathrm{K}^{+}$and $\mathrm{K}^{-}$IEs. (A) Gold particle clusters decorate the exterior surface of $\mathrm{K}^{+}$IE plasma membrane immediately adjacent to electron dense knobby protrusions (see arrows). Gold particle clusters are observed in the $\mathrm{K}^{-}$clone on the exterior face of IEs (see arrows), although no electron dense knobby protrusions are present. Bars, $200 \mathrm{nM}$. (B) The distribution of the numbers of gold particle clusters per IE was determined for both $\mathrm{K}^{+}$and $\mathrm{K}^{-}$clones. The 25 th-75th percentile of the distribution (box), the mean (line within box) and overall range of this distribution is indicated. (C) The distribution of gold particles within each cluster was determined for $\mathrm{K}^{+}$and $\mathrm{K}^{-}$IEs. The 25 th- 75 th percentile of the distribution (box), the mean (line within box) and overall range of this distribution is indicated.

\section{PfEMP1 is distributed in small discrete clusters in both} $\mathrm{K}^{+}$and $\mathrm{K}^{-} \mathrm{IES}$

TEM was used to examine the distribution of PfEMP1 in $\mathrm{K}^{+}$ and $\mathrm{K}^{-}$IEs in detail. Immuno-gold labelling with mAbBC6 to type 41 PfEMP1 $\mathrm{K}^{+}$IEs indicated discrete clusters of gold particles on the exterior surface of the IE plasma membrane associated with electron-dense knobby protrusions (Fig. 6A). The approximately $30 \mathrm{~nm}$ separation between the surface of the knobs and gold particle labelling is consistent with the separation expected from the use of a triple layer antibody detection technique. Interestingly, not all knob structures were decorated with gold particle clusters. A count of knobs on 200 trophozoite IEs (a stage where PfEMP1 export to the IE surface is complete) indicated that only $30 \%$ of knobs were labelled. Even accounting for the possibility that the gold-labelled $\operatorname{IgG}$ moiety is within a different plane to that of the knob, data presented here suggest that a large number of knobs are not loaded with PfEMP1.

Immuno-gold labelling of $\mathrm{K}^{-}$IEs similarly indicated discrete clusters of gold particles approximately $30 \mathrm{~nm}$ from the exterior surface of the IE (Fig. 6A). The gold particle clusters did not appear to lie adjacent to any electron dense structures within the IE plasma membrane. Initial examination appeared to suggest many fewer clusters of gold particles on $\mathrm{K}^{-}$IEs than $\mathrm{K}^{+}$IEs. A count of 200 IEs from three independent labelling experiments of $\mathrm{K}^{+}$ and $\mathrm{K}^{-}$clones indicated that this was indeed the case, with $\mathrm{K}^{-}$IEs having approximately half the number of clusters (Fig. 6B). This significant reduction $(P<0.001)$ in the number of PfEMP1 clusters alone may account for the overall reduction in PfEMP1 on the surface of $\mathrm{K}^{-}$IEs. However, the number of gold particles within each cluster was counted as a surrogate indicator of whether the relative size of PfEMP1 clusters in $\mathrm{K}^{+}$and $\mathrm{K}^{-}$IEs differs. This analysis revealed no significant difference $(P=0.148)$ in the distribution of numbers of gold particles in clusters from $\mathrm{K}^{+}$and $\mathrm{K}^{-}$IEs (Fig. 6C).

\section{Ultrastructural examination of the interaction between $\mathrm{K}^{+}$and $\mathrm{K}^{-}$IEs and HDMECs}

Adhesion of type 41 PfEMP1-expressing $\mathrm{K}^{+}$ and $\mathrm{K}^{-}$IEs was examined in detail using TEM of IEs adhering to HDMECs grown as a monolayer on coverslips (Fig. 7). Ultrastructural examination of the interface between the IE and the endothelial cell surface revealed that in both $\mathrm{K}^{+}$and $\mathrm{K}^{-}$IEs the surface was flattened against the endothelial cell with evidence of filamentous electron dense connections between the two cells (Fig. 7B,C) (Scholander et al., 1996). In K ${ }^{+}$IEs the electron dense filaments project from the raised surface of the knobs (Fig. 7B), whereas in $\mathrm{K}^{-}$IEs the filamentous projections showed no obvious association with any structure (Fig. 7C). The connection between the IE and endothelial cell surfaces consistently appears to be approximately $25 \mathrm{~nm}$; although with knobs projecting some $25 \mathrm{~nm}$ above the $\mathrm{K}^{+}$IE surface the actual distance between these IEs and the endothelial cell increases to approximately $50 \mathrm{~nm}$.

Using freeze-fracture the distribution of intramembraneous particles (IMP) on the cytoplasmic P-face of the erythrocyte plasma membrane was examined in $\mathrm{K}^{+}$and $\mathrm{K}^{-}$IE. Extensive remodelling of the $\mathrm{K}^{+}$IE cytoskeleton, and in particular clustering of Band 3 protein, gives rise to an uneven distribution of IMP with the appearance of a concentric ring structure immediately below the site of knob formation (Fig. 8A,B) (Allred et al., 1986). This clearly contrasts with $\mathrm{K}^{-}$IEs where there is no apparent reorganisation of IMP on the P-face of the erythrocyte plasma membrane, which has 

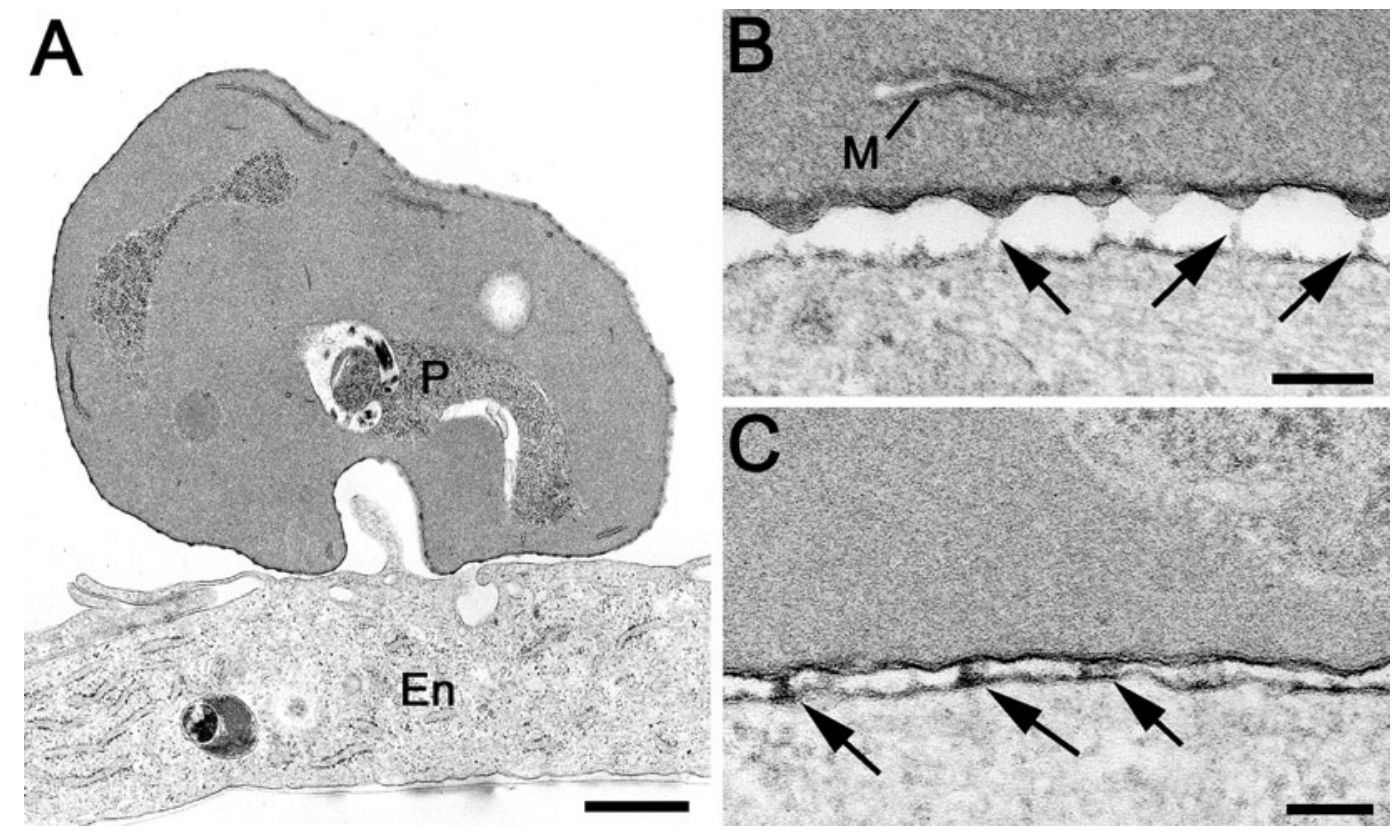

Fig. 7. TEM of the

IE-endothelial-cell interaction in $\mathrm{K}^{+}$and $\mathrm{K}^{-}$IEs. (A) Lowpower micrograph of a $\mathrm{K}^{+} \mathrm{IE}$ (P) that is adhering to the surface of an endothelial cell (En). Bar, $1 \mu \mathrm{m}$. (B) Detail of the interface between a $\mathrm{K}^{+} \mathrm{IE}$ and an endotheial cell showing strands of connecting material specifically located at knobs (arrows). Note the presence of a Maurer's Cleft (M). Bar, 100 nm. (C) Interface between a $\mathrm{K}^{-} \mathrm{IE}$ and an endothelial cell in which individual clumps of electron dense material can be seen forming connections between the plasma membranes of the IE and endothelial cell (arrows). Bar, $100 \mathrm{~nm}$.

the same appearance as an uninfected erythrocyte (Fig. 8CE).

\section{Discussion}

Both in vitro and in vivo data indicate that knobs play a key role in the IE cytoadhesive process. Not only does their absence result in reduced levels of adhesion in vitro, but in vivo data indicate a strong functional selection for knobs since $\mathrm{K}^{-} \mathrm{IEs}$ are not observed unless the patient is splenectomised (Langreth and Peterson, 1985; Pongponratn et al., 2003). $\mathrm{K}^{-}$IEs are readily generated during in vitro culture when spontaneous truncation of one end of chromosome 2 typically deletes kahrp, a gene encoding the major structural component of knobs, and the genes located telomeric to it. The key role for KAHRP in knob formation was demonstrated when targeted knockout of kahrp resulted in $\mathrm{K}^{-}$IEs (Crabb et al., 1997). Kahrp-knockout parasites also adhere poorly under flow conditions. Since KAHRP interacts non-covalently with both PfEMP1 and components of the IE cytoskeleton, a model for reduced adhesion in $\mathrm{K}^{-}$IEs was proposed suggesting that absence of this bridging molecule prevents stress forces developed under flow being transmitted from PfEMP1 to the IE cytoskeleton (Crabb et al., 1997). Data presented here clearly indicate that $\mathrm{K}^{-}$clones display approximately half the amount of PfEMP1 on the surface than do $\mathrm{K}^{+}$clones. Both immuno-TEM and labelling of PfEMP1 by iodination provide direct evidence for the extent of this reduction in PfEMP1 expression in $\mathrm{K}^{-}$clones, with western blots and flow cytometry providing strong supporting evidence. Thus, we would suggest a more parsimonious explanation for reduced adhesion in $\mathrm{K}^{-}$IEs; reduced levels of adhesion in $\mathrm{K}^{-}$IEs are the result of less PfEMP1 being displayed on the host erythrocyte surface.

The reduction of surface-exposed PfEMP1 in $\mathrm{K}^{-}$IEs appears to be a consequence of two factors: first, a reduced total pool of PfEMP1 is available in $\mathrm{K}^{-} \mathrm{IEs}$; and second, an apparent reduction in the trafficking of this pool of PfEMP1 to the IE surface. These processes are probably linked, with reduced efficiency of PfEMP1 export providing feedback that results in a smaller total pool of PfEMP1 being ultimately available. The similar steady state levels of type 41 and 6 var transcript in $\mathrm{K}^{+}$ and $\mathrm{K}^{-}$clones would support the notion that this phenotype is mediated through a post-transcriptional mechanism. The genes deleted following truncation of chromosome 2 in the $\mathrm{K}^{-}$clones may provide some clues for this apparent reduction in PfEMP1 trafficking. Downstream of the kahrp deletion site is the gene encoding PfEMP3, a protein previously implicated in the efficient export of PfEMP1 (Waterkeyn et al., 2000). PfEMP3 shares homology with Usop1, a tethering protein necessary for vesicle docking. Although pfemp 3 knockouts still export PfEMP1 to the IE surface, overexpression of a truncated gene product did result in reduced PfEMP1 export. Further downstream of pfemp 3 are three genes (PFB0080c, PFB0085c and PFB0090c), which all contain a DNA J domain implicated in protein-protein interactions (www.PlasmoDB.org) (Gardner et al., 2002). Interestingly, PFB0090c encodes a $40 \mathrm{kDa}$ protein with homology to chaperonins and expression profiling indicates that this gene is transcribed in ring stage IE. However, deletion of kahrp itself may prove to be key. The absence of KAHRP in the $\mathrm{K}^{-}$clones described here as well as in the kahrpknockout parasites both correlate with reduced adhesion under flow. Although reduced levels of PfEMP1 expression were not formerly described by $\mathrm{Crabb}$ and colleagues, evidence provided suggests that the kahrp-knockout parasites have a reduced pool of PfEMP1 (Crabb et al., 1997). Taken together, these data suggest that in the absence of KAHRP less PfEMP1 is expressed on the $\mathrm{K}^{-}$IE surface. KAHRP may therefore play some role in efficient PfEMP1 export to the IE surface - a proposal also supported by a recent report characterising the trafficking of a PfEMP1-GFP fusion protein to the IE surface (Knuepfer et al., 2005).

Reduced levels of adhesion under conditions of flow have been similarly observed following pfemp 3 deletion, although like the kahrp knockout the level of static adhesion did not 
Fig. 8. Freeze-fracture examination of the distribution of intra-membraneous particles (IMP) on the plasma membrane $\mathrm{P}$-face in $\mathrm{K}^{+}$and $\mathrm{K}^{-} \mathrm{IE}$.

(A) Low power micrograph of a $\mathrm{K}^{+} \mathrm{IE}$ in which the fracture plane passes through the erythrocyte plasma membrane and cytoplasm to the membrane of the parasitophorous vacuole (PV), which contains the parasite. Note that there is an uneven distribution of the intramembraneous particle (IMP) within the erythrocyte plasma membrane (arrowheads). Bar, 1 $\mu \mathrm{m}$. (B) Detail of a fracture through a $\mathrm{K}^{+} \mathrm{IE}$ plasma membrane. Note the concentric ring formed from focal organisation of IMP and a zone free of IMP. IMP form foci at sites underlying knob (arrowheads). Bar, $100 \mathrm{~nm}$. (C) Low power micrograph of a $\mathrm{K}^{-}$IE in which the fracture plane passes through the erythrocyte plasma membrane and cytoplasm to reveal the parasitophorous vacuole (PV). Bar, $1 \mu \mathrm{m}$. (D) Detail of the $\mathrm{K}^{-}$ erythrocyte plasma membrane (boxed area in C) showing the even distribution of IMP in the absence of knob formation. Bar, $100 \mathrm{~nm}$. (E) Detail of the plasma membrane of an uninfected erythrocyte for comparison to D to illustrate the lack of IMP rearrangement in the absence of knobs. Bar, $100 \mathrm{~nm}$.
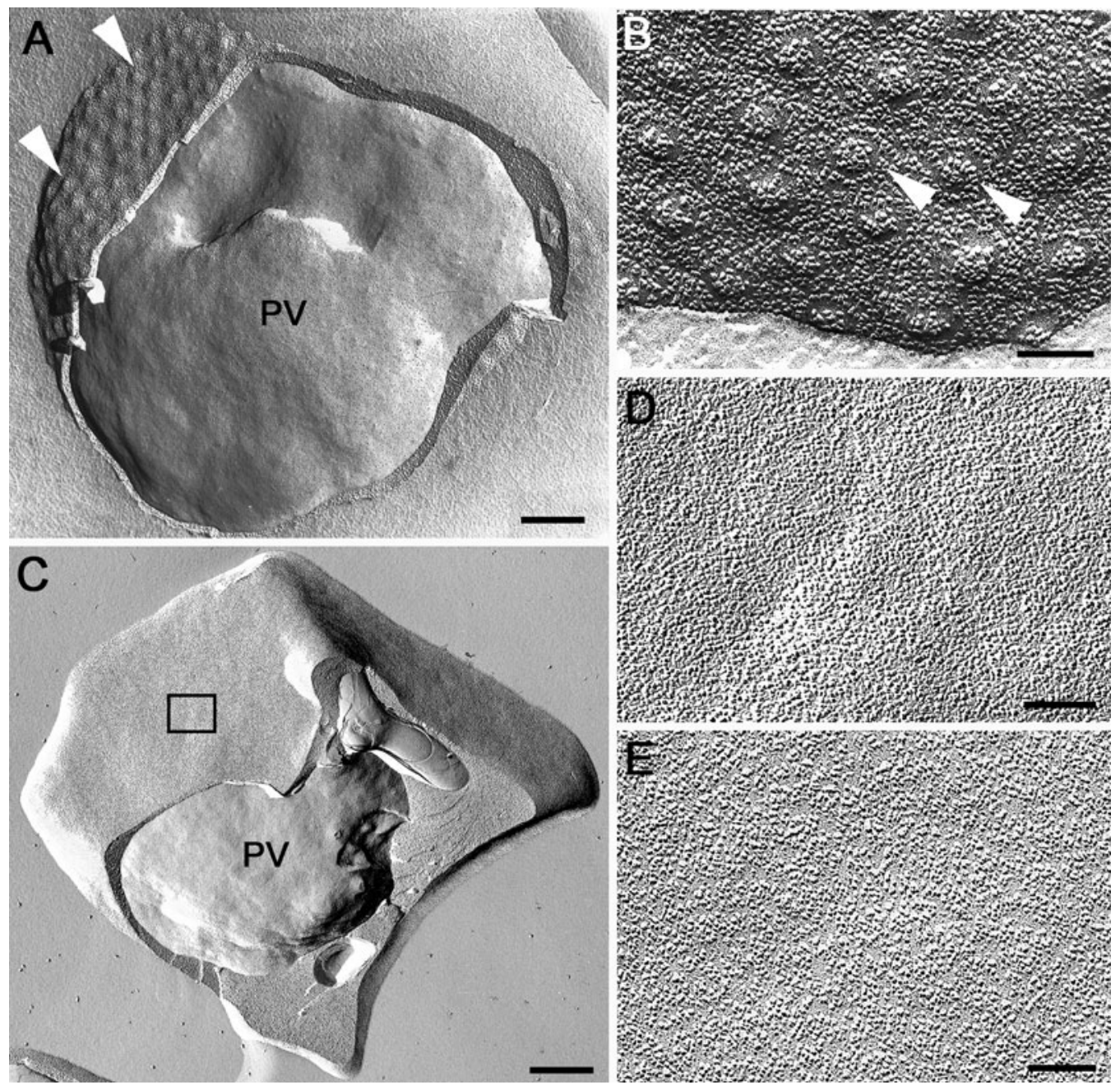

appear to be altered (Cooke et al., 2002a; Crabb et al., 1997; Waterkeyn et al., 2000). The observation that both static and flow adhesion are reduced in the $\mathrm{K}^{-}$clones used here, irrespective of the PfEMP1 variant expressed, suggests that deletion of kahrp and pfemp3, as well any of the eighteen further genes located subtelomeric to them, may have an additive effect in reduction of PfEMP1 export in $\mathrm{K}^{-} \mathrm{IE}$.

Although less PfEMP1 is displayed on the surface of $\mathrm{K}^{-} \mathrm{IEs}$, our data suggest that its basic distribution and biophysical properties appear unaltered compared with that of PfEMP1 expressed on the surface of $\mathrm{K}^{+}$IEs. IFA data suggest a punctate distribution over the IE surface, with TEM micrographs indicating discrete clumps of PfEMP1, albeit not associated with knobs in $\mathrm{K}^{-}$IEs. Control experiments carried out labelling $\mathrm{K}^{+}$and $\mathrm{K}^{-}$IEs over a range of temperatures $\left(4-37^{\circ} \mathrm{C}\right)$ gave the same pattern of fluorescence signal (data not shown), eliminating the possibility that clustering of PfEMP1 is an artefact arising during the three layer staining protocol. Thus, in the absence of knobs, how is PfEMP1 organised in clusters? PfEMP1 may self aggregate, although how this process would be controlled to give the restricted size distribution of PfEMP1 clusters observed is unclear. Alternatively, knob-associated proteins other than those deleted in the $\mathrm{K}^{-}$clones used here may mediate PfEMP1 clustering. Examination of the P-face of the IE plasma membrane in $\mathrm{K}^{-}$IEs, however, shows no indication of IMP rearrangement that would suggest the presence of an incomplete or partial structure onto which PfEMP1 would be organised. It is more likely that PfEMP1 associates with the IE cytoskeleton immediately following its export to the IE surface, effectively tethering the newly exported PfEMP1 together in one place. Several lines of evidence support this proposal. First, membrane proteins in IEs have a substantially reduced ability to laterally diffuse, a result of higher order oligomerisation, association with ankyrin and spectrin and steric impediments imposed by the IE cytoskeleton (Parker et al., 2004). Data presented here indicate that not only does PfEMP1 in $\mathrm{K}^{+}$and $\mathrm{K}^{-}$IEs appear effectively static within the IE plasma membrane, but it also shares coextraction properties of cytoskeletal proteins in both Triton X100 and urea. Indeed, recent reports have suggested that PfEMP1 may not be a classical integral membrane protein, but is rather transported and inserted into the IE membrane as part of a larger protein complex (Papakrivos et al., 2005; Knuepfer et al., 2005). Second, unusual small proteinaceous vesicles 
have been observed to lie between Maurer's clefts and the IE plasma membrane (Kriek et al., 2003; Wickert et al., 2003). The discrete clusters of PfEMP1 observed may therefore represent the entire PfEMP1 content of individual vesicles following their fusion with the plasma membrane.

In conclusion, data presented suggest that the mechanisms underlying the enhanced adhesion that $\mathrm{K}^{+}$IEs display over $\mathrm{K}^{-}$ IEs need to be critically re-evaluated. The static nature of PfEMP1 clusters in the IE plasma membrane suggests that in $\mathrm{K}^{+}$IEs, PfEMP1 export occurs directly to either nascent or preformed knobs. Transmission electron microscopy of $\mathrm{K}^{+}$IEs indicates that approximately two-thirds of knobs are not loaded with PfEMP1. The limited window of PfEMP1 export to the IE surface (16-24 hpi) compared with a much longer window of knob formation (16-40 hpi) would perhaps favour a model where nascent knobs formed during the window of PfEMP1 export are loaded. In the absence of knobs, PfEMP1 export is less efficient and consequently less PfEMP1 is loaded on the $\mathrm{K}^{-} \mathrm{IE}$ surface, correspondingly impacting on their ability to mediate adhesion. Understanding the mechanism whereby PfEMP1 remains clustered in $\mathrm{K}^{-}$IEs may shed further light on the mechanism of export of this important parasite virulence factor to the IE surface.

The authors acknowledge and thank Alister Craig for his discussions during the course of the work and for access to flow adhesion apparatus in his laboratory. This work was funded through a Wellcome Trust Programme Grant to C.I.N.

\section{References}

Allred, D. R., Gruenberg, J. E. and Sherman, I. W. (1986). Dynamic rearrangements of erythrocyte membrane internal architecture induced by infection with Plasmodium falciparum. J. Cell Sci. 81, 1-16.

Baruch, D. I., Pasloske, B. L., Singh, H. B., Bi, X., Ma, X. C., Feldman, M., Taraschi, T. F. and Howard, R. J. (1995). Cloning the $P$. falciparum gene encoding PfEMP1, a malarial variant antigen and adherence receptor on the surface of parasitized human erythrocytes. Cell 82, 77-87.

Biggs, B. A., Culvenor, J. G., Ng, J. S., Kemp, D. J. and Brown, G. V. (1989a). Plasmodium falciparum: cytoadherence of a knobless clone. Exp. Parasitol. 69, 189-197.

Biggs, B. A., Kemp, D. J. and Brown, G. V. (1989b). Subtelomeric chromosome deletions in field isolates of Plasmodium falciparum and their relationship to loss of cytoadherence in vitro. Proc. Natl. Acad. Sci. USA 86, 2428-2432.

Bull, P. C., Lowe, B. S., Kortok, M., Molyneux, C. S., Newbold, C. I. and Marsh, K. (1998). Parasite antigens on the infected red cell surface are targets for naturally acquired immunity to malaria. Nat. Med. 4, 358-360.

Cooke, B., Coppel, R. and Wahlgren, M. (2000). Falciparum malaria: sticking up, standing out and out-standing. Parasitol. Today 16, 416-420.

Cooke, B. M., Glenister, F. K., Mohandas, N. and Coppel, R. L. (2002a). Assignment of functional roles to parasite proteins in malaria-infected red blood cells by competitive flow-based adhesion assay. Br. J. Haematol. 117, 203-211.

Cooke, B. M., Coppel, R. L. and Nash, G. B. (2002b). Analysis of the adhesive properties of Plasmodium falciparum-infected red blood cells under conditions of flow. Methods Mol. Med. 72, 561-569.

Coppel, R. L., Cooke, B. M., Magowan, C. and Narla, M. (1998). Malaria and the erythrocyte. Curr. Opin. Hematol. 5, 132-138.

Crabb, B. S., Cooke, B. M., Reeder, J. C., Waller, R. F., Caruana, S. R., Davern, K. M., Wickham, M. E., Brown, G. V., Coppel, R. L. and Cowman, A. F. (1997). Targeted gene disruption shows that knobs enable malaria-infected red cells to cytoadhere under physiological shear stress. Cell 89, 287-296.

Crandall, I., Guthrie, N., Demers, D. and Sherman, I. W. (1994). Plasmodium falciparum: CD36 dependent cytoadherence or rosetting of infected erythrocytes is modulated by knobs. Cell Adhes. Commun. 2, 503510
Deitsch, K. W. and Wellems, T. E. (1996). Membrane modifications in erythrocytes parasitized by Plasmodium falciparum. Mol. Biochem. Parasitol. 76, 1-10.

Fried, M. and Duffy, P. E. (1996). Adherence of Plasmodium falciparum to chondroitin sulfate A in the human placenta. Science 272, 1502-1504.

Gardner, J. P., Pinches, R. A., Roberts, D. J. and Newbold, C. I. (1996). Variant antigens and endothelial receptor adhesion in Plasmodium falciparum. Proc. Natl. Acad. Sci. USA 93, 3503-3508.

Gardner, M. J., Hall, N., Fung, E., White, O., Berriman, M., Hyman, R. W., Carlton, J. M., Pain, A., Nelson, K. E., Bowman, S. et al. (2002). Genome sequence of the human malaria parasite Plasmodium falciparum. Nature 419, 498-511.

Gruenberg, J., Allred, D. R. and Sherman, I. W. (1983). Scanning electron microscope-analysis of the protrusions (knobs) present on the surface of Plasmodium falciparum-infected erythrocytes. J. Cell Biol. 97, 795-802.

Horrocks, P., Pinches, R., Kyes, S., Kriek, N., Lee, S., Christodoulou, Z. and Newbold, C. I. (2002). Effect of var gene disruption on switching in Plasmodium falciparum. Mol. Microbiol. 45, 1131-1141.

Horrocks, P., Pinches, R., Christodoulou, Z., Kyes, S. A. and Newbold, C. I. (2004a). Variable var transition rates underlie antigenic variation in malaria. Proc. Natl. Acad. Sci. USA 101, 11129-11134.

Horrocks, P., Kyes, S., Pinches, R., Christodoulou, Z. and Newbold, C. (2004b). Transcription of subtelomerically located var gene variant in Plasmodium falciparum appears to require the truncation of an adjacent var gene. Mol. Biochem. Parasitol. 134, 193-199.

Johnson, D., Gunther, K., Ansorge, I., Benting, J., Kent, A., Bannister, L., Ridley, R. and Lingelbach, K. (1994). Characterization of membrane proteins exported from Plasmodium falciparum into the host erythrocyte. Parasitology 109 (Pt 1), 1-9.

Knapp, B., Hundt, E. and Kupper, H. A. (1990). Plasmodium falciparum aldolase: gene structure and localization. Mol. Biochem. Parasitol. 40, 1-12.

Knuepfer, E., Rug, M., Klonis, N., Tilley, L. and Cowman, A. F. (2005). Trafficking of the major virulence factor to the surface of transfected $P$. falciparum-infected erythrocytes. Blood 105, 4078-4087.

Kriek, N., Tilley, L., Horrocks, P., Pinches, R., Elford, B. C., Ferguson, D. J., Lingelbach, K. and Newbold, C. I. (2003). Characterization of the pathway for transport of the cytoadherence-mediating protein, PfEMP1, to the host cell surface in malaria parasite-infected erythrocytes. Mol. Microbiol. 50, 1215-1227.

Kyes, S., Pinches, R. and Newbold, C. (2000). A simple RNA analysis method shows var and rif multigene family expression patterns in Plasmodium falciparum. Mol. Biochem. Parasitol. 105, 311-315.

Kyes, S., Horrocks, P. and Newbold, C. (2001). Antigenic variation at the infected red cell surface in malaria. Annu. Rev. Microbiol. 55, 673-707.

Kyes, S. A., Christodoulou, Z., Raza, A., Horrocks, P., Pinches, R., Rowe, J. A. and Newbold, C. I. (2003). A well-conserved Plasmodium falciparum var gene shows an unusual stage-specific transcript pattern. Mol. Microbiol. 48, 1339-1348.

Langreth, S. G. and Peterson, E. (1985). Pathogenicity, stability, and immunogenicity of a knobless clone of Plasmodium falciparum in Colombian owl monkeys. Infect. Immun. 47, 760-766.

Langreth, S. G., Jensen, J. B., Reese, R. T. and Trager, W. (1978). Fine structure of human malaria in vitro. J. Protozool. 25, 443-452.

Lanzer, M., Wertheimer, S. P., de Bruin, D. and Ravetch, J. V. (1994). Chromatin structure determines the sites of chromosome breakages in Plasmodium falciparum. Nucleic Acids Res. 22, 3099-3103.

Magowan, C., Nunomura, W., Waller, K. L., Yeung, J., Liang, J., van Dort, H., Low, P. S., Coppel, R. L. and Mohandas, N. (2000). Plasmodium falciparum histidine-rich protein 1 associates with the band 3 binding domain of ankyrin in the infected red cell membrane. Biochim. Biophys. Acta. 1502, 461-470.

Marsh, K. and Howard, R. J. (1986). Antigens induced on erythrocytes by P. falciparum: expression of diverse and conserved determinants. Science 231, 150-153.

Nagao, E., Kaneko, O. and Dvorak, J. A. (2000). Plasmodium falciparuminfected erythrocytes: qualitative and quantitative analyses of parasiteinduced knobs by atomic force microscopy. J. Struct. Biol. 130, 34-44.

Newbold, C., Warn, P., Black, G., Berendt, A., Craig, A., Snow, B., Msobo, M., Peshu, N. and Marsh, K. (1997). Receptor-specific adhesion and clinical disease in Plasmodium falciparum. Am. J. Trop. Med. Hyg. 57, 389398.

Newbold, C., Craig, A., Kyes, S., Rowe, A., Fernandez-Reyes, D. and Fagan, T. (1999). Cytoadherence, pathogenesis and the infected red cell surface in Plasmodium falciparum. Int. J. Parasitol. 29, 927-937. 
Oh, S. S., Voigt, S., Fisher, D., Yi, S. J., LeRoy, P. J., Derick, L. H., Liu, S. and Chishti, A. H. (2000). Plasmodium falciparum erythrocyte membrane protein 1 is anchored to the actin-spectrin junction and knob-associated histidine-rich protein in the erythrocyte skeleton. Mol. Biochem. Parasitol. 108, 237-247.

Papakrivos, J., Newbold, C. and Lingelbach, K. (2005). A potential novel mechanism for the insertion of a membrane protein revealed by a biochemical analysis of the Plasmodium falciparum cytoadherence molecule PfEMP1. Mol. Microbiol. 55, 1272-1284.

Parker, P. D., Tilley, L. and Klonis, N. (2004). Plasmodium falciparum induces reorganization of host membrane proteins during intraerythrocytic growth. Blood 103, 2404-2406.

Pongponratn, E., Turner, G. D., Day, N. P., Phu, N. H., Simpson, J. A., Stepniewska, K., Mai, N. T., Viriyavejakul, P., Looareesuwan, S., Hien, T. T. et al. (2003). An ultrastructural study of the brain in fatal Plasmodium falciparum malaria. Am. J. Trop. Med. Hyg. 69, 345-359.

Raventos-Suarez, C., Kaul, D. K., Macaluso, F. and Nagel, R. L. (1985). Membrane knobs are required for the microcirculatory obstruction induced by Plasmodium falciparum-infected erythrocytes. Proc. Natl. Acad. Sci. USA 82, 3829-3833.

Roberts, D. J., Craig, A. G., Berendt, A. R., Pinches, R., Nash, G., Marsh, K. and Newbold, C. I. (1992). Rapid switching to multiple antigenic and adhesive phenotypes in malaria. Nature 357, 689-692.

Rogerson, S. J., Grau, G. E. and Hunt, N. H. (2004). The microcirculation in severe malaria. Microcirculation 11, 559-576.

Scholander, C., Treutiger, C. J., Hultenby, K. and Wahlgren, M. (1996) Novel fibrillar structure confers adhesive property to malaria-infected erythrocytes. Nat. Med. 2, 204-208.

Trager, W. and Jensen, J. B. (1976). Human malaria parasites in continuous culture. Science 193, 673-675.

Turner, G. D., Morrison, H., Jones, M., Davis, T. M., Looareesuwan, S., Buley, I. D., Gatter, K. C., Newbold, C. I., Pukritayakamee, S., Nagachinta, B. et al. (1994). An immunohistochemical study of the pathology of fatal malaria. Evidence for widespread endothelial activation and a potential role for intercellular adhesion molecule-1 in cerebral sequestration. Am. J. Pathol. 145, 1057-1069.

Udomsangpetch, R., Aikawa, M., Berzins, K., Wahlgren, M. and Perlmann, P. (1989). Cytoadherence of knobless Plasmodium falciparuminfected erythrocytes and its inhibition by a human monoclonal antibody. Nature 338, 763-765.

Urban, B. C., Ferguson, D. J., Pain, A., Willcox, N., Plebanski, M., Austyn, J. M. and Roberts, D. J. (1999). Plasmodium falciparum-infected erythrocytes modulate the maturation of dendritic cells. Nature 400, 73-77.

Waller, K. L., Cooke, B. M., Nunomura, W., Mohandas, N. and Coppel, R. L. (1999). Mapping the binding domains involved in the interaction between the Plasmodium falciparum knob-associated histidine-rich protein (KAHRP) and the cytoadherence ligand $P$. falciparum erythrocyte membrane protein 1 (PfEMP1). J. Biol. Chem. 274, 23808-23813.

Waller, K. L., Nunomura, W., Cooke, B. M., Mohandas, N. and Coppel, R. L. (2002). Mapping the domains of the cytoadherence ligand Plasmodium falciparum erythrocyte membrane protein 1 (PfEMP1) that bind to the knob-associated histidine-rich protein (KAHRP). Mol. Biochem. Parasitol. 119, 125-129.

Waterkeyn, J. G., Wickham, M. E., Davern, K. M., Cooke, B. M., Coppel, R. L., Reeder, J. C., Culvenor, J. G., Waller, R. F. and Cowman, A. F. (2000). Targeted mutagenesis of Plasmodium falciparum erythrocyte membrane protein 3 (PfEMP3) disrupts cytoadherence of malaria-infected red blood cells. EMBO J. 19, 2813-2823.

Wickert, H., Wissing, F., Andrews, K. T., Stich, A., Krohne, G. and Lanzer, M. (2003). Evidence for trafficking of PfEMP1 to the surface of $P$. falciparum-infected erythrocytes via a complex membrane network. Eur. J. Cell Biol. 82, 271-284.

Wickham, M. E., Rug, M., Ralph, S. A., Klonis, N., McFadden, G. I., Tilley, L. and Cowman, A. F. (2001). Trafficking and assembly of the cytoadherence complex in Plasmodium falciparum-infected human erythrocytes. EMBO J. 20, 5636-5649. 